\title{
Correction to: Theory to practice: Prospective mathematics teachers' recontextualizing discourses surrounding collective argumentation
}

\author{
Carlos Nicolas Gomez Marchant ${ }^{1}$ (D) - Hyejin Park ${ }^{2}$ - Yuling Zhuang ${ }^{3}$. \\ Jonathan Foster ${ }^{4}$. AnnaMarie Conner ${ }^{4}$
}

Published online: 20 June 2021

(c) Springer Nature B.V. 2021

\section{Correction to: Journal of Mathematics Teacher Education https://doi.org/10.1007/s10857-021-09500-9}

In the original publication of the article, the affiliations of both the authors AnnaMarie Conner and Jonathan K. Foster's are incorrectly published.

The affiliations of both the authors are corrected in this correction.

AnnaMarie Conner: Department of Mathematics and Science Education, University of Georgia.

Jonathan K. Foster's affiliation: Department of Mathematics and Science Education, University of Georgia. Please update in the author's list of affiliations

"The original article has been corrected.".

Publisher's Note Springer Nature remains neutral with regard to jurisdictional claims in published maps and institutional affiliations.

The original article can be found online at https://doi.org/10.1007/s10857-021-09500-9.

Carlos Nicolas Gomez Marchant

nico.gomez@utexas.edu

1 Department of Curriculum and Instruction, The University of Texas at Austin, Austin, TX 78712, USA

2 Department of Mathematics and Statistics, James Madison University, Harrisonburg, VA 22807, USA

3 College of Engineering, University of Georgia, Athens, GA 30602, USA

4 Department of Mathematics and Science Education, University of Georgia, Athens, GA 30602, USA 